\title{
The Prevalence and Components of Metabolic Syndrome in Men from Infertile Couples and Its Relation on Semen Analysis
}

This article was published in the following Dove Press journal: Diabetes, Metabolic Syndrome and Obesity: Targets and Therapy

\author{
Minh Tam Le iD ${ }^{1,2}$ \\ Nhu Quynh Thi Tran (D) \\ Nguyen Dac Nguyen (iD' \\ Quoc Huy Vu Nguyen (D) 2 \\ 'Center for Reproductive Endocrinology \\ and Infertility, Hue University of Medicine \\ and Pharmacy, Hue University, Hue, \\ Vietnam; ${ }^{2}$ Department of OBGYN, Hue \\ University of Medicine and Pharmacy, \\ Hue University, Hue, Vietnam
}

Purpose: Metabolic syndrome (MetS) has been reported as a deleterious factor in male fertility potential, associated with hypogonadism, impaired spermatogenesis, decreased sperm concentration and motility, and increased sperm DNA damage. This study aimed to determine the prevalence of MetS in men from infertile couples and evaluate its effect on semen analysis (SA).

Participants and Methods: A cross-sectional descriptive study was performed in men from infertile couples diagnosed based on the World Health Organization 2010 criteria and treated at the Hue Center for Reproductive Endocrinology and Infertility, Vietnam. General information included medical history, lifestyle, MetS factors, SA, and sperm DNA fragmentation test were collected. Based on the diagnostic criteria of the American Heart Association and the National Heart, Lung, and Blood Institute for Asian men, the study population was divided into two groups: MetS and non-MetS groups. The outcomes were analyzed for any relationship between MetS and the SA index and the DNA fragmentation index (DFI).

Results: A total of 534 men from infertile couples were included in this study. The prevalence of MetS was 23.4\%, and abnormal semen analysis accounted for $93.8 \%$. Age, body mass index (BMI), waist-to-hip ratio (WHR), waist-to-height ratio (WHtR), hepatitis $\mathrm{B}$ and total cholesterol were related to the occurrence of MetS in infertile men $(p<0.05)$. MetS did not reveal any impact on the parameters of SA. There was a positive correlation between waist circumference (WC), WHR, WHtR, and systolic blood pressure (BP) with abnormal sperm head and DFI $(\mathrm{p}<0.05)$.

Conclusion: Although the prevalence of MetS was remarkable in men from infertile couples, there was no association between MetS and semen quality. However, WC, WHR, WHtR, and systolic BP were found to be significantly associated with abnormal sperm head and DFI.

Keywords: prevalence, metabolic syndrome, infertility, sperm, semen analysis

\section{Introduction}

According to the World Health Organization (WHO), infertility occurs in approximately $8-12 \%$ of couples, among which $20-45 \%$ of the causes are related to male factors. ${ }^{1,2}$ Basic factors responsible for reduced male fertility potential may include oxidative stress, genetic abnormalities, systemic diseases, varicocele, infections or a high exposure to biological substances lifestyle, and tobacco. ${ }^{3}$ The underlying mechanism whereby these factors affect infertility potential may involve sperm parameters and DNA fragmentation.
Correspondence: Minh Tam Le Center for Reproductive Endocrinology and Infertility, Hue University of Medicine and Pharmacy, Hue University, 06 Ngo

Quyen Street, Hue, Vietnam

Tel +84989228779

Fax +842343822 I73

Email leminhtam@huemed-univ.edu.vn 
Apart from advanced male age, which is accepted as a physiological factor of lowering sperm quality and higher rates of sperm DNA fragmentation, ${ }^{4}$ obesity has been identified as a factor affecting men's reproductive function by metabolizing adverse biological substances that can reduce the blood testosterone and sex hormone-binding globulin (SHBG) concentration. This leads to feedback on the hypothalamus-pituitary-testis, which negatively affects the function of Leydig cells and spermatogenesis. Furthermore, oxidative stress can cause various changes in blood flow to the testis and endocrine disorders. ${ }^{5}$

Metabolic syndrome (MetS) is referred to as a group of systemic disorders that includes obesity, insulin resistance, hypertension, and dyslipidemia. It is defined as the presence of at least three of five criteria: high fasting glucose, abdominal obesity, high blood pressure, hypertriglyceridemia, and low high-density lipoprotein-cholesterol (HDL-C). ${ }^{6}$ Previous published studies revealed that obesity adversely affects male fertility. ${ }^{7,8}$ Robeva et al concluded that insulin resistance reduced blood testosterone levels in men. ${ }^{9}$ In addition, there was a statistically significant association between metabolic dysfunction and changes in testosterone and SHBG levels. Other studies have shown that metabolic disorders decrease sexual function due to erectile dysfunction. ${ }^{10,11}$ The study by Dupont et al in 2019 on 196 infertile men concluded that MetS was an independent factor that could have a negative effect on the quality of sperm. ${ }^{12}$ A meta-analysis in 2012 found that overweight or obesity, which is a component of MetS, was associated with an increased risk of azoospermia and oligozoospermia. ${ }^{13}$

To date, inconsistent hypotheses suggest that obesity might be related to an underlying metabolic pathology. In addition, metabolic disorders affect more health problems than fertility. ${ }^{14}$ It is also a risk factor for cardiovascular disease, type II diabetes, stroke, chronic kidney disease, and cancer. ${ }^{15,16}$ Although, there have been some publications on obesity and metabolic disorders in male subfertility in the past two decades, the data are still limited and inconsistent. The influence of MetS on male reproductive function still needs to be elucidated. This study aimed to determine the prevalence of MetS in Vietnamese men from infertile couples and its effect on semen analysis.

\section{Participants and Methods}

\section{Participant Selection}

This cross-sectional descriptive study included male partners of infertile couples who had been examined and treated at the Hue Center of Reproductive Endocrinology and Infertility, Hue University Hospital, Vietnam, from January 2018 to August 2020. The inclusion criteria were as follows: (1) diagnosed with infertility according to the WHO standards as having regular sex without any contraception but still unable to get pregnant after 12 months, (2) having full clinically relevant information, blood biochemistry (including fasting blood glucose and lipidemia test, semen analysis (SA), sperm DNA fragmentation test), and (3) consenting to participate in the study. The exclusion criteria were as follows: (1) acute urogenital tract infections or being treated for a malignancy affecting spermatogenesis, (2) retrograde ejaculation, inability to ejaculate, and (3) no testis detected through clinical examination and scrotum ultrasound.

\section{Study Design}

In this cross-sectional research, the rate estimate investigation was used to calculate the sample size $n=Z_{\frac{\alpha}{2}}^{2} \frac{p(1-p)}{\Delta^{2}}$ The expected prevalence of MetS in the infertile men group of the Kristel Ehala-Aleksejev's12 study in 2018 was $17.8 \%$ with $Z(1-\alpha / 2)=2.58$, corresponds to $99 \%$ confidence interval (CI), $\Delta=0.05$, the minimum sample size required to estimate the prevalence of MetS was 390 men. A total of 534 men from infertile cases were recruited to the study group.

Based on the 2005 diagnostic criteria of the American Heart Association and the National Heart, Lung, and Blood Institute-Adult Treatment Panel III (AHA/NHLBIATP III) for Asian men, the study population was divided into two groups: MetS group $(\mathrm{n}=125)$ and non-MetS group $(n=409)$. Patients from both groups were examined for baseline characteristics including age, body mass index (BMI), hip circumference, waist-to-hip ratio (WHR), waist-to-height ratio (WHtR), and blood pressure. Infertile men were then subjected to various assays to evaluate reproductive capacity: biochemical assays, semen analysis, and halosperm tests.

\section{Anthropometry and Blood Pressure}

Each participant was measured for height and weight. BMI was calculated as body weight in kilograms divided by the square of height in meters. BMI values were categorized based on the Asian-specific classification for BMI status, as underweight $\left(<18.5 \mathrm{~kg} / \mathrm{m}^{2}\right)$, normal $\left(18.5-22.9 \mathrm{~kg} / \mathrm{m}^{2}\right)$, overweight $\left(23.0-24.9 \mathrm{~kg} / \mathrm{m}^{2}\right)$, and obese $\left(\geq 25 \mathrm{~kg} / \mathrm{m}^{2}\right)$. Waist circumference (WC) was measured by a flexible tape as follow: the patients stood up and removed any 
bulky clothing; then, the tape was wrapped across the belly button, gently on the skin. The measurement was taken while exhaling after breathing gently. The same measuring tape was also used to measure hip circumference by wrapping the tape around the widest part of the hip, with the tape plane parallel to the ground. WHR was the ratio of waist circumference (in $\mathrm{cm}$ ) divided by the hip circumference (in cm). Similarly, WHtR was calculated by the waist circumference (in $\mathrm{cm}$ ) divided by the height (in $\mathrm{cm}$ ).

Basic blood pressure was measured using a mercury sphygmomanometer (ALP K2, Tokyo, Japan) after a 5-minute rest. Patients were in a sitting position, with both feet flat on the ground and the arm resting at chest height. The heart rate in beats per minute was recorded before inflating the cuff by pumping the bulb and then slowly open the valve to drop the pressure. The systolic (SBP) and diastolic blood pressure (DBP) were determined after two additional measurements. Patients did not eat or drink for at least $30 \mathrm{mins}$ before and did not talking during the measurement.

\section{Biochemical Assays}

Sampling: The blood sample was collected in the morning after an overnight fast. For sample taking and preparation, only suitable tubes or equipment were used such as Liheparin and K2-EDTA serum, and anticoagulant plasma. The sample types listed were tested with a set of selective sampling tubes, commercially available at the time of the test. Different manufacturer's sample tubes may be made of different materials that can influence the test results in some cases. Samples in the primary tubes were handled according to the tube manufacturer's instructions, and samples containing precipitates were centrifuged before performing the assay. Roche/Hitachi Cobas systems (Module CO-BAS 4000/6000, Roche Diagnostics, Indianapolis, IN, USA) was used to measure fasting glucose levels and blood lipid levels, including total cholesterol, triglycerides, high-density lipoprotein-cholesterol (HDL-C), and low-density lipoprotein-cholesterol (LDL-C). All measurements were performed at the Hue University Hospital laboratory as per manufacturer instructions.

\section{Semen Analysis}

The SA was performed after 2 to 7 days of sexual abstinence and the sample was collected by masturbation and ejaculated into a sterile, wide-mouthed container. After that, the samples were immediately transported to the laboratory and placed in a warming incubator at $37^{\circ} \mathrm{C}$ while the semen liquefied. To avoid changes in temperature that may affect sperm quality, the samples were macroscopically and microscopically examined within 1 $\mathrm{h}$ after sample collection. The microscopic examination included sperm concentration, motility, mortality, and morphology following the WHO 2010 standards. ${ }^{18}$ The morphology assessment concerns the variations in head size and shape or the various midpiece and tail defects. Abnormal head rate was calculated as abnormal sperm head divided total number of abnormal morphology of the sperm. The SA was performed manually by two welltrained and andrologists with 10-year experiences in SA. Furthermore, to prevent bias, the percentages of the two independent assessments were considered by calculating the average and difference of the two percentages of normal forms from the replicated assessments to determine the acceptability of the difference based on the WHO guideline. ${ }^{17}$ If the difference was too high, the assessment was repeated on the same slides. Otherwise, we reported the average percentage to the nearest whole number.

\section{Halosperm Test}

The Halosperm ${ }^{\circledR}$ HT-HS10, provided by Halotech (Halotech DNA SL, Madrid, Spain), was used to evaluate the DNA fragmentation index. The sample was diluted to a concentration of 5-10 million spermatozoa $/ \mathrm{mL}$. Next, a $25 \mu \mathrm{L}$ sample was added to the agarose Eppendorf and then placed onto a microscope slide that was covered with a glass coverslip. This slide was stored at $4^{\circ} \mathrm{C}$ for $5 \mathrm{~min}$. Subsequently, the slide was incubated in another tray with $10 \mathrm{~mL}$ of tempered lysis solution for $25 \mathrm{~min}$ and consecutively placed in $70 \%$ ethanol, $90 \%$ ethanol, and $100 \%$ ethanol every 2 min. After drying, the sample was observed under a fluorescence microscope. The number on each slide was calculated and a total of 500 spermatozoa were counted; those with DNA fragmentation were identified according to the manufacturer's instructions, and the DNA fragmentation index (DFI) was calculated as indicated below.

$$
\operatorname{DFI}(\%)=100 \times \frac{\begin{array}{l}
\text { No.of spermatozoa } \\
\text { with fragmented DNA }
\end{array}}{\begin{array}{l}
\text { No.of spermatozoa } \\
\text { counted }
\end{array}}
$$

\section{Metabolic Syndrome}

The diagnosis of MetS was based on the AHA/NHLBIATP III guidelines for Asians. MetS was defined when 
there were at least three of the five following criteria: WC $\geq 90 \mathrm{~cm}$, arterial blood pressure $\geq 130 / 85 \mathrm{mmHg}$, triglyceride $\geq 1.7 \mathrm{mmol} / \mathrm{L}, \mathrm{HDL}-\mathrm{C}<1.03 \mathrm{mmol} / \mathrm{L}$, and fasting glucose $\geq 5 \mathrm{mmol} / \mathrm{L}^{6}$

\section{Statistical Analysis}

SPSS software version 22.0. (SPSS Inc., Chicago, IL, USA) was used to analyze all statistics. Numerical data are presented as mean \pm standard deviation and percentages. Variation test analysis was used to compare mean values and percentages between the two study groups using the $t$-test and Pearson Chi-square test. The correlation between the parameters of MetS and sperm quality was expressed by Spearman correlation coefficient (rho). Fischer's exact test was used in the correlation analysis of MetS and Hepatitis B infection and age-adjusted logistic regression were used to compare MetS and non-MetS groups. $\mathrm{P}$ values $<0.05$ were considered statistically significant.

The present study was approved by the Ethics Committee of Hue University of Medicine and Pharmacy, approval number H2019/436. Written consent was obtained from all participants before data collection, in accordance with the Declaration of Helsinki.

\section{Results}

A total of 534 men from infertile couples who fulfilled the inclusion criteria were enrolled in this study. The general characteristics of the study population with and without MetS are shown in Table 1. The mean age was $34.7 \pm 6.3$ years. The prevalence of MetS in males from infertile couples was $23.4 \%$ In the group with MetS, there were statistically significant differences in the proportion of males with age of 35 years and above (13.3\% vs $10.1 \%$, $\mathrm{p}=0.004)$, BMI from 23 and above $(16.9 \%$ vs $6.6 \%, \mathrm{p}<$ $0.001)$, waist circumference from $90 \mathrm{~cm}$ and above $(16.5 \%$ vs $6.9 \%, \mathrm{p}<0.001)$ WHR from 0.9 and above $(15.2 \%$ vs $8.2 \%, \mathrm{p}<0.001)$ Compared to the non-MetS group, men in the MetS group had a higher percentage of increased SBP $(6.6 \%$ vs $4.3 \%, \mathrm{p}<0.001)$ as well as increased DBP (3.9\% vs $1.1 \%, \mathrm{p}<0.001)$.

There was a significant difference between men with and without MetS, respectively, in total cholesterol $(5.27 \pm$ 1.03 vs $4.77 \pm 0.93, \mathrm{p}<0.001)$; triglycerides $(3.65 \pm 1.78$ vs $1.85 \pm 1.15, \mathrm{p}<0.001)$; LDL-C $(1.02 \pm 0.22$ vs $1.33 \pm$ $0.40, \mathrm{p}<0.001)$ and fasting glucose $(6.08 \pm 1.18$ vs $5.36 \pm$ $0.87, \mathrm{p}<0.001)$. However, there was no significant difference in smoking, alcohol consumption, or LDL-C concentration between the two groups.

Table 2 and Figure 1 present the value of predictors of MetS in men from infertile couples using univariate analysis. The factor with the largest area under the curve (AUC) was WHtR (AUC $=0.78$ ) with a sensitivity (Se) of $72 \%$ and a specificity $(\mathrm{Sp})$ of $76.5 \%, \mathrm{p}<0.001$. Hip circumference had an AUC of 0.77 ( $\mathrm{Se}=84 \%, \mathrm{Sp}=$ $60.6 \%, \mathrm{p}<0.001)$. The remaining factors including weight, BMI and WHR were also significant univariant predictors of MetS; however, they were not related to MetS after age-adjusted logistic regression multivariate analysis, except for HC (Table 3)

Table 4 presents the relation of anthropometric factors, metabolic components and SA results. There was no significant difference between abnormal SA results and male age, WC, WHR, WHtR, blood pressure, lipidemia tests or fasting glucose, except for smoking. Abnormal SA in men with smoking was significantly higher compared to that in men without smoking (51.9\% vs $30.1 \%, \mathrm{p}=0.046)$.

Regarding the relationship between semen parameters and metabolic syndrome, there was no relationship between semen volume, sperm concentration, PR motility, vitality, morphology, or sperm DNA fragmentation index and the presence of MetS (Table 5).

Furthermore, the present study found a slight correlation between WHR, systolic BP, and abnormal head rate (rho $=0.095$ and 0.115 , respectively; $\mathrm{p}<0.05$ ), and a positive correlation between WC, WHR, WHtR, and DFI (rho $=0.094,0.095$, and 0.101, respectively; $\mathrm{p}<0.05$ ), as shown in Table 6 .

\section{Discussion}

This study detected a $23.4 \%$ prevalence of MetS in men from infertile couples based on AHA/NHLBI-ATP III guidelines, which was higher than the $10-17 \%$ in previous publications. ${ }^{17,19}$ These differences can result from the study participates's race, as well as the differences in diagnostic criteria for Asian and international men $(\mathrm{WC} \geq 90 \mathrm{~cm}$ versus $\mathrm{WC} \geq 102 \mathrm{~cm}$ ) and/or lifestyles. The present study also reported a relationship between age, BMI, HC, WHR, WHtR, hepatitis $B$ infection, and MetS ( $p<0.05)$. However, after adjusting for age, we found that BMI was not related to MetS $(p>0.05)$. The average age of this sample was $34.7 \pm$ 6.3 years, and there was a significant difference in age between the MetS and non-MetS groups $(p=0.006)$. The incidence of MetS was lower in the group under the 
Table I Distribution of General Characteristics of the Study Population with and without Metabolic Syndrome

\begin{tabular}{|c|c|c|c|c|}
\hline \multirow[t]{2}{*}{ Factors } & \multirow[t]{2}{*}{ Total $(n=534)$} & \multicolumn{2}{|c|}{ Metabolic Syndrome } & \multirow[t]{2}{*}{$P$-value* } \\
\hline & & MetS $(n=125)$ & Non-MetS $(n=409)$ & \\
\hline Age (years) & $34.7 \pm 6.3$ & $36.1 \pm 6.6$ & $34.3 \pm 6.1$ & 0.006 \\
\hline$<35$ & 291 (54.5\%) & $54(10.1 \%)$ & 237 (44.4\%) & 0.004 \\
\hline$\geq 35$ & $243(45.5 \%)$ & 71 (13.3\%) & $172(32.2 \%)$ & \\
\hline BMI (kg/m2) & $23.2 \pm 2.9$ & $25.1 \pm 2.6$ & $22.6 \pm 2.8$ & $<0.001$ \\
\hline$<23$ & $310(58.1 \%)$ & $35(6.6 \%)$ & 275 (5I.5\%) & $<0.001$ \\
\hline$\geq 23$ & 224 (4I.9\%) & $90(16.9 \%)$ & $134(25.1 \%)$ & \\
\hline WC (cm) & $83.6 \pm 8.4$ & $90.1 \pm 7.2$ & $81.6 \pm 7.7$ & $<0.001$ \\
\hline$<90$ & $386(72.3 \%)$ & $37(6.9 \%)$ & 349 (65.4\%) & $<0.001$ \\
\hline$\geq 90$ & 148 (27.7\%) & $88(16.5 \%)$ & $60(11.2 \%)$ & \\
\hline $\mathrm{HC}(\mathrm{cm})$ & $95.5 \pm 6.3$ & $99.9 \pm 5.6$ & $94.2 \pm 5.9$ & $<0.001$ \\
\hline WHR & $0.88 \pm 0.06$ & $0.90 \pm 0.05$ & $0.87 \pm 0.07$ & $<0.001$ \\
\hline$<0.9$ & $350(65.5 \%)$ & 44 (8.2\%) & $306(57.3 \%)$ & $<0.001$ \\
\hline$\geq 0.9$ & I 84 (34.5\%) & 81 (15.2\%) & $103(19.3 \%)$ & \\
\hline WHtR & $0.50 \pm 0.05$ & $0.54 \pm 0.04$ & $0.49 \pm 0.05$ & $<0.001$ \\
\hline \multicolumn{5}{|l|}{ Hepatitis B virus } \\
\hline Positive & $38(7.1 \%)$ & $2(0.4 \%)$ & $36(6.7 \%)$ & 0.005 \\
\hline Negative & 496 (92.9\%) & $123(23.0 \%)$ & $373(69.9 \%)$ & \\
\hline Blood pressure & & & & $<0.001$ \\
\hline SBP $(\mathrm{mmHg})$ & $115.4 \pm 10.2$ & $120.4 \pm 13.0$ & $113.9 \pm 8.6$ & \\
\hline$<130$ & 476 (89.1\%) & 90 (16.8\%) & $386(72.3 \%)$ & $<0.001$ \\
\hline$\geq 130$ & $58(10.9 \%)$ & $35(6.6 \%)$ & $23(4.3 \%)$ & \\
\hline $\mathrm{DBP}(\mathrm{mmHg})$ & $73.3 \pm 7.4$ & $77.5 \pm 8.9$ & $72.1 \pm 6.3$ & $<0.001$ \\
\hline$<85$ & 507 (95.0\%) & 104 (19.5\%) & 403 (75.0\%) & $<0.001$ \\
\hline$\geq 85$ & $27(5.0 \%)$ & $21(3.9 \%)$ & $6(1.1 \%)$ & \\
\hline \multicolumn{5}{|l|}{ Smoking } \\
\hline No & $348(65.2 \%)$ & $8 \mathrm{I}(\mathrm{I} 5.2 \%)$ & $267(50.0 \%)$ & 0.92 \\
\hline Yes & I $86(34.8 \%)$ & 44 (8.2\%) & $142(26.6 \%)$ & \\
\hline \multicolumn{5}{|l|}{ Alcohol consumption } \\
\hline No & $245(45.9 \%)$ & $55(10.3 \%)$ & $190(35.6 \%)$ & 0.63 \\
\hline Yes & $289(54.1 \%)$ & $70(13.1 \%)$ & $219(41.0 \%)$ & \\
\hline \multicolumn{5}{|l|}{ Lipidemia } \\
\hline Total cholesterol (nmol/L) & $4.89 \pm 0.98$ & $5.27 \pm 1.03$ & $4.77 \pm 0.93$ & $<0.001$ \\
\hline Triglyceride (nmol/L) & $2.27 \pm 1.53$ & $3.65 \pm 1.78$ & $1.85 \pm 1.15$ & $<0.001$ \\
\hline LDL - Cholesterol (nmol/L) & $1.26 \pm 0.39$ & $3.45 \pm 0.94$ & $3.27 \pm 0.90$ & 0.059 \\
\hline HDL - Cholesterol (nmol/L) & $3.31 \pm 0.91$ & $1.02 \pm 0.22$ & $1.33 \pm 0.40$ & $<0.001$ \\
\hline Fasting glucose (nmol/L) & $5.53 \pm 1.00$ & $6.08 \pm 1.18$ & $5.36 \pm 0.87$ & $<0.001$ \\
\hline
\end{tabular}

Notes: Data are presented as mean \pm SD or number (\%). *Comparison was performed between men with and without Met $S$ using the independent-samples $t$-test and Chisquare test or Fisher exact test with so small sample (under 5) in one cell.

Abbreviations: BMI, body mass index; DBP, diastolic blood pressure; HC, hip circumference; HDL-C, high-density lipoprotein cholesterol; LDL-C, low-density lipoprotein cholesterol; MetS, metabolic syndrome; SBP, systolic blood pressure; WC, waist circumference; WHR, waist-to-hip ratio; WHtR, waist-to-height ratio.

age of 35 years compared with that of the group over 35 years of age $(p=0.004)$. Previous studies have also reported that advanced age has a negative impact on MetS in the general population. ${ }^{20,21}$
BMI is the most widely used conventional measure of obesity because of its close relationship to the body fat. However, BMI itself cannot distinguish muscle, fat mass, or the distribution of body fat; therefore, the value of BMI 
Table 2 Predictors of MetS in Men from Infertile Couples Using Univariate Analysis

\begin{tabular}{|l|c|c|c|c|c|}
\hline Factors & AUC & J-Value & Se (\%) & Sp (\%) & P-value \\
\hline Weight & 0.76 & 67.50 & 69.6 & 72.6 & $<0.001$ \\
HC & 0.77 & 95.50 & 84.0 & 60.6 & $<0.001$ \\
BMI & 0.75 & 23.67 & 72.0 & 67.2 & $<0.001$ \\
WHR & 0.71 & 0.90 & 64.8 & 74.6 & $<0.001$ \\
WHtR & 0.78 & 0.52 & 72.0 & 76.5 & $<0.001$ \\
\hline
\end{tabular}

Note: Data are presented as percentage (\%).

Abbreviations: AUC, area under curve; BMI, body mass index; HC, hips circumference; Se, sensitivity; Sp, specificity; WHR, waist-to-hip ratio; WHtR, waist-toheight ratio.

in the diagnosis of MetS remains controversial. Our data revealed other factors related to body fat, such as $\mathrm{HC}$, WHR, and WHtR, which can be accepted as prognostic values of MetS. Specifically, $\mathrm{HC}$ at $95.5 \mathrm{~cm}(\mathrm{AUC}=$ $0.769 ; \mathrm{Se}=84.0 \% ; \mathrm{Sp}=60.6 \%)$, WHR at $0.90(\mathrm{AUC}=$ 0.714; $\mathrm{Se}=64.8 \% ; \mathrm{Sp}=74.6 \%)$ and WHtR at $0.52(\mathrm{AUC}$ $=0.784 ; \mathrm{Se}=72.0 \% ; \mathrm{Sp}=76.5 \%)(\mathrm{p}<0.05)$ significantly predicted MetS. Therefore, the highest specificity and sensibility factors for MetS were the HC and WHtR, respectively.

The correlation between chronic HBV infection and MetS has been a concern in recent years. A metaanalysis of 13 studies with a total of 138,994,999 cases concluded that chronic HBV infection is associated with a reduced risk of MetS (odds ratio $[\mathrm{OR}]=0.83$; confidence interval $[\mathrm{CI}] 95 \%=0.71-0.79 ; \mathrm{p}<0.001){ }^{22}$ To explain the

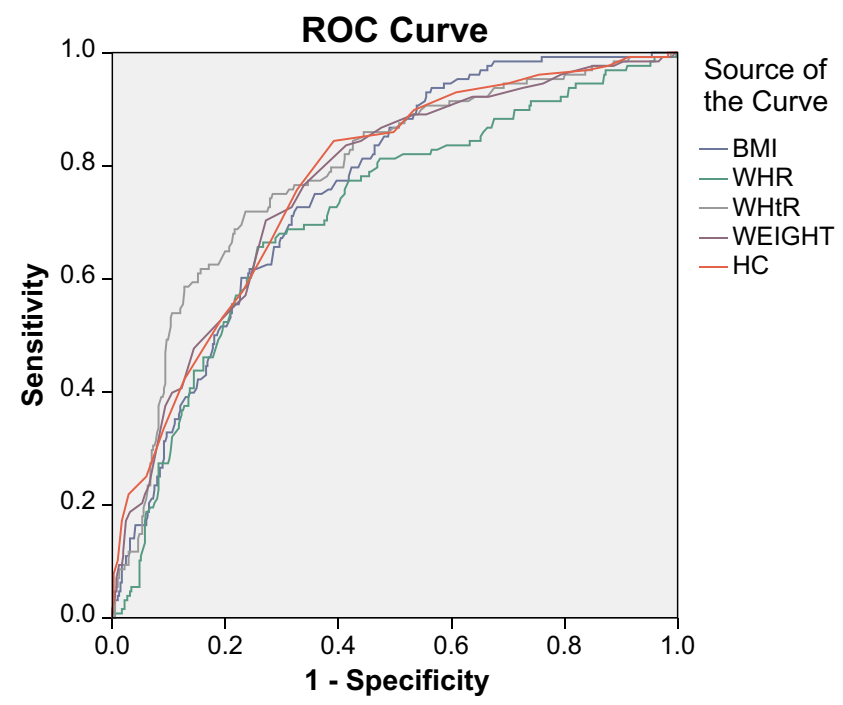

Figure I Comparison of ROC curves between weight, height, hips circumference, BMI, WHR and WHtR, in prediction of MetS in men from infertile couples using univariate analysis. Diagonal segments are produced by ties.

Abbreviations: ROC, receiver operating characteristic; BMI, body mass index; WHR, waist-to-hip ratio; WHtR, waist-to-height ratio; MetS, metabolic syndrome.
Table 3 Predictors of MetS in Men from Infertile Couples Using Logistic Regression Analysis

\begin{tabular}{|l|c|c|c|c|}
\hline \multirow{2}{*}{ Factors } & \multirow{2}{*}{ OR } & \multicolumn{2}{|c|}{ Cl 95\% } & \multirow{2}{*}{ P-value } \\
\cline { 3 - 4 } & & Lower & Upper & \\
\hline Age & 1.055 & 1.018 & 1.093 & 0.004 \\
Weight & 1.023 & 0.968 & 1.081 & 0.426 \\
HC & 1.140 & 1.077 & 1.207 & $<0.001$ \\
BMI & 1.149 & 0.984 & 1.341 & 0.079 \\
\hline
\end{tabular}

Note: $\mathrm{P}$-value was age-adjusted $\mathrm{p}$ value by using logistic regression.

Abbreviations: $\mathrm{BMI}$, body mass index; $\mathrm{HC}$, hips circumference; $\mathrm{Cl}$, confidence interval; OR, odds ratio.

role of chronic HBV infection in lipid metabolism through the liver, reports have shown that one of the effects of the $\mathrm{HBV} X$ protein derived from the HBV genome is cell suppression. The liver secretes apolipoprotein B-100, an important glycoprotein for the transport of very lowdensity lipoprotein and low-density lipoprotein, which leads to a decrease in the concentration of triglycerides in the blood. ${ }^{23,24}$ The decrease in blood triglyceride levels contributes to a reduced risk of MetS. Interestingly, our data also revealed a negative relationship between HBV infection and MetS.

In 2010, a cross-sectional study by Keszthelyi et al analyzing 1169 semen samples of infertile couples in Budapest showed that both BMI and WHR were significantly related to semen concentration and total sperm count. $^{25}$ This finding was different from our results and their mean BMI and WHR were significantly higher compared to our data $\left(26.8 \mathrm{~kg} / \mathrm{m}^{2}\right.$ versus $23.2 \mathrm{~kg} / \mathrm{m}^{2} ; 0.94$ versus 0.88 , respectively). However, other studies demonstrated that MetS did not affect to quality of sperm, similar to our conclusion. ${ }^{19,26,27}$

Although there was no significant relationship between abnormal SA in general and MetS, our data showed a correlation between the individual elements. Both SBP and WHR affected sperm abnormal morphology $(\mathrm{p}<0.05)$. Hypertension is known to negatively affect sperm quality through a compound called clusterin as apo-lipoprotein J. The presence of surface heterodimeric clusterin in the human spermatozoa was a marker for poor sperm quality of morphologically abnormal and DNA fragmentation. ${ }^{28-30}$ Dockery et al concluded that androgen deficiency might be the cause of high blood pressure due to the increase in arterial stiffness. ${ }^{31}$ Other studies have demonstrated a negative relationship between blood pressure and testosterone levels, as well as spermatogenesis. ${ }^{32,33}$ Eisenberg et al suggested that men with hypertensive disorder had higher rates of abnormal 
Table 4 The Relation of Anthropometric Factors, Metabolic Components and Semen Analysis Results

\begin{tabular}{|c|c|c|c|c|}
\hline \multirow[t]{2}{*}{ Factors } & \multirow[t]{2}{*}{ Total $(n=534)$} & \multicolumn{2}{|c|}{ Semen Analysis } & \multirow[t]{2}{*}{$P$-value* } \\
\hline & & Abnormal $(n=348)$ & Normal $(n=96)$ & \\
\hline Age (years) & & $34.8 \pm 6.4$ & $34.6 \pm 5.6$ & 0.82 \\
\hline$<35$ & $291(54.5 \%)$ & $239(44.8 \%)$ & $52(9.7 \%)$ & 0.94 \\
\hline$\geq 35$ & $243(45.5 \%)$ & $199(37.3 \%)$ & 44 (8.2\%) & \\
\hline WC (cm) & & $83.5 \pm 8.6$ & $84.2 \pm 7.7$ & 0.45 \\
\hline$<90$ & $386(72.3 \%)$ & 317 (59.4\%) & $69(12.9 \%)$ & 0.92 \\
\hline$\geq 90$ & 148 (27.7\%) & $|2|(22.7 \%)$ & 27 (5.0\%) & \\
\hline WHR & & $0.87 \pm 0.07$ & $0.88 \pm 0.05$ & 0.68 \\
\hline$<0.9$ & $350(65.5 \%)$ & 287 (53.7\%) & 63 (II.8\%) & 0.99 \\
\hline$\geq 0.9$ & I84 (34.5\%) & I5I (28.3\%) & $33(6.2 \%)$ & \\
\hline WHtR & & $0.50 \pm 0.05$ & $0.50 \pm 0.05$ & 0.41 \\
\hline \multicolumn{5}{|l|}{ Blood pressure } \\
\hline SBP $(\mathrm{mmHg})$ & & $115.2 \pm 10.3$ & $116.5 \pm 9.7$ & 0.26 \\
\hline $\mathrm{DPB}(\mathrm{mmHg})$ & & $73.2 \pm 7.6$ & $73.85 \pm 6.4$ & 0.45 \\
\hline \multicolumn{5}{|l|}{ Lipidemia tests } \\
\hline Total cholesterol (nmol/L) & & $4.88 \pm 1.00$ & $4.95 \pm 0.86$ & 0.52 \\
\hline Triglyceride $(\mathrm{nmol} / \mathrm{L})$ & & $2.25 \pm 1.56$ & $2.37 \pm 1.40$ & 0.46 \\
\hline LDL-Cholesterol (nmol/L) & & $3.30 \pm 0.92$ & $3.36 \pm 0.86$ & 0.55 \\
\hline HDL- Cholesterol (nmol/L) & & $1.25 \pm 0.39$ & $1.29 \pm 0.40$ & 0.34 \\
\hline Fasting glucose (nmol/L) & & $5.53 \pm 1.02$ & $5.55 \pm 0.89$ & 0.85 \\
\hline \multicolumn{5}{|l|}{ Hepatitis B virus } \\
\hline Positive & $38(7.1 \%)$ & $30(5.6 \%)$ & $8(1.5 \%)$ & 0.65 \\
\hline Negative & $496(92.9 \%)$ & $408(76.4 \%)$ & $88(16.5 \%)$ & \\
\hline \multicolumn{5}{|l|}{ Smoking } \\
\hline Yes & $186(34.8 \%)$ & 161 (30.1\%) & $25(4.7 \%)$ & 0.046 \\
\hline No & $348(65.2 \%)$ & 277 (51.9\%) & $7 \mid(13.3 \%)$ & \\
\hline \multicolumn{5}{|l|}{ Alcohol consumption } \\
\hline Yes & $289(54.1 \%)$ & $230(43.1 \%)$ & 59 (11.0\%) & 0.11 \\
\hline No & 245 (45.9\%) & $208(39.0 \%)$ & 37 (6.9\%) & \\
\hline MetS & $125(23.4 \%)$ & 99 (I8.5\%) & $26(4.9 \%)$ & 0.35 \\
\hline Non-MetS & $409(76.6 \%)$ & $339(63.5 \%)$ & 70 (13.1\%) & \\
\hline
\end{tabular}

Notes: Data are presented as mean \pm SD or number (\%). *Comparison was performed between men with and without MetS using the independent-samples $t$-test and Chisquare test.

Abbreviations: BMI, body mass index; DBP, diastolic blood pressure; HC, Hip circumference; HDL-C, high-density lipoprotein cholesterol; LDL-C, low-density lipoprotein cholesterol; MetS, metabolic syndrome; SBP, systolic blood pressure; WC, waist circumference; WHR, waist-to-hip ratio; WHtR, waist-to-height ratio.

SA. ${ }^{34}$ Our study found that a higher SBP could lead to a higher abnormal head sperm $(r h o=0.115, p=0.010)$, and that a higher WHR was related to a higher abnormal head sperm (rho $=0.095, p=0.034)$. This detection is valuable in the prognosis of fertility potential regarding the relationship between sperm morphology and metabolic disorders.

Cigarette smoke contains harmful components such as carbon monoxide, nitrogen oxide, ammonia and nicotine. Nicotine has been shown to harm sperm quality, including semen volume, sperm concentration, motility, and antioxidant activity as well as male reproductive hormone. ${ }^{35,36}$ However, the negative effect of smoking on semen parameters is still controversial. ${ }^{37,38}$ A positive correlation was also observed between cigarette smoking and sperm DNA fragmentation among patients receiving infertility counseling. ${ }^{37}$ Our result in this study could not establish any relationship between smoking and SA (Table 4). 
Table 5 The Relationship Between Semen Parameters and Metabolic Syndrome

\begin{tabular}{|c|c|c|c|c|c|}
\hline \multirow[t]{2}{*}{ Semen Parameters } & \multirow[t]{2}{*}{ Total $(n=534)$} & \multicolumn{2}{|c|}{ Metabolic Syndrome } & \multirow[t]{2}{*}{$P$-value* } & \multirow[t]{2}{*}{ PI-value } \\
\hline & & MetS & Non-MetS & & \\
\hline Azoospermia & $33(6.2 \%)$ & 7 (l.3\%) & $26(4.9 \%)$ & 0.76 & 0.784 \\
\hline Volume (mL) & & $1.9 \pm 1.0$ & $2.0 \pm 1.0$ & 0.21 & 0.146 \\
\hline$<\mathrm{I} .5$ & $163(32.5 \%)$ & $44(8.8 \%)$ & 119 (23.7\%) & 0.21 & \\
\hline$\geq 1.5$ & $338(67.5 \%)$ & $74(14.8 \%)$ & $264(52.7 \%)$ & & \\
\hline Sperm concentration $\left(\times 10^{6} / \mathrm{mL}\right)$ & & $34.1 \pm 15.0$ & $31.4 \pm 15.4$ & 0.09 & 0.105 \\
\hline$<15$ & $60(12.0 \%)$ & $9(1.8 \%)$ & $51(10.2 \%)$ & 0.09 & \\
\hline$\geq 15$ & $44 \mid(88.0 \%)$ & $109(21.7 \%)$ & $332(66.3 \%)$ & & \\
\hline Total sperm count $\left(x \mid 0^{6}\right)$ & & $62.5 \pm 47.2$ & $61.7 \pm 44.7$ & 0.87 & 0.803 \\
\hline PR motility (\%) & & $31.4 \pm 12.4$ & $29.7 \pm 11.7$ & 0.19 & 0.114 \\
\hline$<32$ & 279 (55.7\%) & 57 (II.4\%) & $222(44.3 \%)$ & 0.07 & \\
\hline$\geq 32$ & $222(44.3 \%)$ & $61(12.2 \%)$ & $161(32.1 \%)$ & & \\
\hline Total PR motility $\left(\times 10^{6}\right)$ & & $21.9 \pm 23.2$ & $20.1 \pm 17.7$ & 0.37 & 0.295 \\
\hline Vitality (\%) & & $78.9 \pm 11.8$ & $79.4 \pm 10.5$ & 0.71 & 0.891 \\
\hline$<58 \%$ & $14(2.8 \%)$ & $6(1.2 \%)$ & $8(1.6 \%)$ & 0.08 & \\
\hline$\geq 58 \%$ & 487 (97.2\%) & $112(22.4 \%)$ & 375 (74.8\%) & & \\
\hline Normal morphology (\%) & & $3.7 \pm 2.1$ & $3.7 \pm 2.2$ & 0.94 & 0.778 \\
\hline$<4 \%$ & 287 (57.3\%) & $63(12.6 \%)$ & 224 (44.7\%) & 0.33 & \\
\hline$\geq 4 \%$ & $214(42.7 \%)$ & 55 (। I.0\%) & $159(31.7 \%)$ & & \\
\hline Abnormal head (\%) & & $86.9 \pm 5.7$ & $87.5 \pm 7.5$ & 0.34 & 0.397 \\
\hline Abnormal neck-tail (\%) & & $57.7 \pm 11.1$ & $57.1 \pm 12.6$ & 0.64 & 0.758 \\
\hline Sperm DFI (\%) & & $25.8 \pm 18.6$ & $25.9 \pm 18.2$ & 0.95 & 0.864 \\
\hline
\end{tabular}

Notes: Data are presented as mean \pm SD or number (\%). *Comparison was performed between men with and without MetS using the independent-samples $t$-test and Chisquare test. PI was age-adjusted P value by using logistic regression. Percentage of semen parameters were calculated in total of $50 \mathrm{I}$ after deducting 33 cases with azoospermia.

Abbreviations: DFI, DNA fragmentation index; PR, progressive; MetS, metabolic syndrome.

Table 6 The Correlation Between Sperm Morphology and DFI with Anthropometry

\begin{tabular}{|l|c|c|c|c|}
\hline \multirow{2}{*}{ Factors } & \multicolumn{2}{|c|}{ Abnormal Sperm Head } & \multicolumn{2}{c|}{ Sperm DFI } \\
\cline { 2 - 5 } & Rho & P-value & Rho & P-value \\
\hline WC $(\mathrm{cm})$ & 0.067 & 0.14 & 0.094 & 0.04 \\
WHR & 0.095 & 0.03 & 0.095 & 0.03 \\
WHtR & 0.061 & 0.18 & 0.101 & 0.03 \\
SBP $(\mathrm{mmHg})$ & 0.115 & 0.01 & -0.037 & 0.41 \\
\hline
\end{tabular}

Note: Pearson's bivariate correlations was used to find the negative or positive relationship.

Abbreviations: DFI, DNA fragmentation index; SBP, systolic blood pressure; WC, waist circumference; $\mathrm{WHR}$, waist-to-hip ratio; $\mathrm{WHtR}$, waist-to-height ratio.

In recent decades, the sperm DNA fragmentation assay was developed as an independent test to evaluate sperm quality, in addition to the traditional SA. A published study in Hue has reported a positive correlation between sperm DNA fragmentation and abnormal head $(p=0.202$, $\mathrm{p}=0.003) .^{39}$ The present study has contributed to this relationship by confirming the effects of increasing WHR on sperm DNA fragmentation (rho $=0.095 ; \mathrm{p}=0.034$ ) as well as the effects of increased WC and WHtR on DFI ( $p$ $<0.05$ ), although WHR and SBP have very weak correlation with abnormal sperm head, as so do WC, WHR and WHtR with sperm DFI $(\mathrm{r}<0.200)$. Wheres another prospective study in 1010 subfertile men found no correlation between sperm DFI and obesity markers such as BMI, WHR, WC, WHtR. ${ }^{40}$ The difference in research population, demographic characteristics, and DFI test might have contributed to these divergent results.

Within the aims of this study, exclusion criteria included any cases with retrograde ejaculation or unejaculation. Theoretically, retrograde ejaculation has been linked to MetS and type 2 diabetes. Therefore, it would be possible to have a functional association between 
retrograde ejaculation or unejaculation in men suffering from MetS. However, the pathogenesis of impaired sperm quality resulting from MetS is outside of this study's purpose. We did not test the male endocrine hormones or measure the reactive oxygen species in these men for further connection between the causal inference. This might be considered a limitation of this study, although the data has confirmed that some components of MetS could have negative effects on sperm quality. Further studies should be performed to evaluate the reactive oxygen species and male reproductive hormonal profiles to better explain the pathogenesis of MetS and reveal the closed correlation between MetS and sperm quality, especially in the male population with advanced age.

\section{Conclusions}

In conclusion, the prevalence of MetS among men from infertile couples in this study is higher compared to other countries. The awareness of this disorders extends beyond reproductive implications. Given the high prevalence of MetS in a quite young male population, further metabolic assessment should be recommended to this specific group of men. Early diagnosis of MetS may provide an advantage of intensified management to halt the progression to long-term complications. We identified $\mathrm{HC}$ as the strongest anthropometric predictor for MetS. Other independent predictors for MetS were WHtR, weight, BMI and WHR. Although the prevalence of MetS was considerable, there was no association between MetS and semen quality in general. WC, WHR, WHtR, and SBP were found to be significantly related to abnormal sperm head and DFI. More studies evaluating the reactive oxygen species and male reproductive hormonal changes may better explain the pathogenesis of MetS and impaired sperm quality.

\section{Abbreviations}

MetS, Metabolic syndrome; SA, semen analysis; DFI, DNA fragmentation index; BMI, body mass index; WHR, waist-to-hip ratio; WHtR, waist-to-height ratio; WC, waist circumference; BP, blood pressure; WHO, World Health Organization; SHBG, sex hormone-binding globulin; HDL-C, high-density lipoprotein-cholesterol; LDL-C, low-density lipoprotein cholesterol; AHA/ NHLBI, American Heart Association and the National Heart, Lung, and Blood Institute; ATP, Adult Treatment Panel III; SBP, systolic blood pressure; DBP, diastolic blood pressure; Se, sensitivity; Sp, specificity.

\section{Data Sharing Statement}

The dataset used and/or analyzed during the current study are available from the corresponding author upon reasonable request.

\section{Ethics Approval and Consent to Participate}

This work was approved by the Hue University of Medicine and Pharmacy Ethics Committee, approval number H2019/436. All patients agreed to participate with written consent forms.

\section{Consent for Publication}

All authors consent to publication

\section{Author Contributions}

All authors made a significant contribution to the work reported, whether that is in the conception, study design, execution, acquisition of data, analysis and interpretation, or in all these areas; took part in drafting, revising or critically reviewing the article; gave final approval of the version to be published; have agreed on the journal to which the article has been submitted; and agree to be accountable for all aspects of the work.

\section{Funding}

This work was supported by a research grant from Vietnam Ministry of Education and Training (grant number DHH2018-04-78). The grantor had no influence in the content of the publication.

\section{Disclosure}

The authors have no competing financial or other interests to declare in relation to this manuscript.

\section{References}

1. Agarwal A, Gupta S, Sharma R. Basic semen analysis. In: Agarwal A, Gupta S, Sharma R, editors. Andrological Evaluation of Male Infertility a Laboratory Guide. New York: Springer; 2016:39-46.

2. Mehra BL, Skandhan KP, Prasad BS, Pawankumar G, Singh G, Jaya V. Male infertility rate: a retrospective study. Urologia. 2018;85:22-24. doi:10.5301/uj.5000254

3. Cho CL, Esteves SC, Agarwal A. Novel insights into the pathophysiology of varicocele and its association with reactive oxygen species and sperm DNA fragmentation. Asian J Androl. 2016;18:186-193. doi:10.4103/1008-682X.170441

4. Stewart AF, Kim ED, Stewart AF, Kim ED. Fertility concerns for the aging male. Urology. 2011;78:496-499. doi:10.1016/j.urology.2011. 06.010 
5. Turner TT, Lysiak JJ. Oxidative stress: a common factor in testicular dysfunction. J Androl. 2008;29:488-498. doi:10.2164/jandrol.108.00 5132

6. Grundy SM, Cleeman JI, Daniels SR, et al. Diagnosis and management of the metabolic syndrome: an American Heart Association/National Heart, Lung, and Blood Institute Scientific Statement. Circulation. 2005;112:2735-2752. doi:10.1161/ CIRCULATIONAHA.105.169404

7. Trayhurn P, Wood IS. Adipokines: inflammation and the pleiotropic role of white adipose tissue. $B r \quad J$ Nutr. 2004;92:347-555. doi:10.1079/BJN20041213

8. Wang P, Mariman E, Renes J, Keijer J. The secretory function of adipocytes in the physiology of white adipose tissue. J Cell Physiol. 2008;216:3-13. doi:10.1002/jcp.21386

9. Robeva R, Kirilov G, Tomova A, Kumanov P. Low testosterone levels and unimpaired melatonin secretion in young males with metabolic syndrome. Andrologia. 2006;38:216-220. doi:10.1111/ j.1439-0272.2006.00743.x

10. Esposito K, Giugliano F, Martedì E, et al. High proportions of erectile dysfunction in men with the metabolic syndrome. Diabetes Care. 2005;28:1201-1203. doi:10.2337/diacare.28.5.1201

11. Corona G, Mannucci E, Petrone L, et al. Association of hypogonadism and type II diabetes in men attending an outpatient erectile dysfunction clinic. Int J Impot Res. 2006;18:190-197. doi:10.1038/ sj.ijir.3901391

12. Dupont C, Faure C, Daoud F, et al. Metabolic syndrome and smoking are independent risk factors of male idiopathic infertility. Basic Clin Androl. 2019;29:9. doi:10.1186/s12610-019-0090-x

13. Sermondade N, Faure C, Fezeu L, Levy R, Czernichow S; ObesityFertility Collaborative Group. Obesity and increased risk for oligozoospermia and azoospermia. Arch Intern Med. 2012;172:440-442. doi:10.1001/archinternmed.2011.1382

14. Heindel JJ, Blumberg B, Cave M, et al. Metabolism disrupting chemicals and metabolic disorders, 2017. Reprod Toxicol. 2017;68:3-33.

15. Alberti KGMM, Eckel RH, Grundy SM, et al. Harmonizing the metabolic syndrome: a joint interim statement of the International Diabetes Federation Task Force on Epidemiology and Prevention; National Heart, Lung, and Blood Institute; American Heart Association; World Heart Federation; International Atherosclerosis Society; and International Association for the Study of Obesity. Circulation. 2009;120:1640-1645. doi:10.1161/ CIRCULATIONAHA.109.192644

16. Grundy SM, Brewer HB Jr, Cleeman JI, et al. Definition of metabolic syndrome: report of the National Heart, Lung, and Blood Institute/ American Heart Association Conference on scientific issues related to definition. Circulation. 2004;109:433-438. doi:10.1161/01. CIR.0000111245.75752.C6

17. World Health Organization. WHO Laboratory Manual for the Examination and Processing of Human Semen. $5^{\text {th }}$ ed. WHO Library Cataloguing-in-Publication Data. WHO Press; 2010.

18. Ehala-Aleksejev K, Punab M. The effect of metabolic syndrome on male reproductive health: a cross-sectional study in a group of fertile men and male partners of infertile couples. PLoS One. 2018;13: e0194395. doi:10.1371/journal.pone.0194395

19. Ventimiglia E, Capogrosso P, Serino A, et al. Metabolic syndrome in White-European men presenting for secondary couple's infertility: an investigation of the clinical and reproductive burden. Asian J Androl. 2017;19:368-373. doi:10.4103/1008-682X.175783

20. Scuteri A, Laurent S, Cucca F, et al. Metabolic syndrome across Europe: different clusters of risk factors. Eur J Pre Cardiol. 2015;22(4):486-491. doi:10.1177/2047487314525529

21. Pucci G, Alcidi R, Tap L, Battista F, Mattace-Raso F, Schillaci G. Sex- and gender-related prevalence, cardiovascular risk and therapeutic approach in metabolic syndrome: a review of the literature. Pharmacol Res. 2017;120:34-42. doi:10.1016/j.phrs.2017.03.008
22. Razi B, Alizadeh S, Omidkhoda A, Imani D, Rezaei R. Association of chronic hepatitis B infection with metabolic syndrome and its components: meta-analysis of observational studies. Diabetes Metab Syndr. 2017;11:S939-S947. doi:10.1016/j.dsx. 2017.07.020

23. Chiang $\mathrm{CH}$, Huang KC. Association between metabolic factors and chronic hepatitis B virus infection. World $J$ Gastroenterol. 2014;20:7213-7216. doi:10.3748/wjg.v20.i23.7213

24. Kang SK, Chung TW, Lee JY, Lee YC, Morton RE, Kim CH. The hepatitis $\mathrm{B}$ virus $\mathrm{X}$ protein inhibits secretion of apolipoprotein $\mathrm{B}$ by enhancing the expression of $\mathrm{N}$-acetylglucosaminyltransferase III. J Biol Chem. 2004;279:28106-28112. doi:10.1074/jbc.M403 176200

25. Keszthelyi M, Gyarmathy VA, Kaposi A, Kopa Z. The potential role of central obesity in male infertility: body mass index versus waist to hip ratio as they relate to selected semen parameters. BMC Public Health. 2020;20:307. doi:10.1186/ s12889-020-8413-6

26. Michalakis K, Mintziori G, Kaprara A, Tarlatzis BC, Goulis DG. The complex interaction between obesity, metabolic syndrome and reproductive axis: a narrative review. Metabolism. 2013;62:457-478.

27. Leisegang K, Udodong A, Bouic PJ, Henkel RR. Effect of the metabolic syndrome on male reproductive function: a case-controlled pilot study. Andrologia. 2014;46:167-176. doi:10. 1111/and.12060

28. Muciaccia B, Sette C, Paronetto MP, et al. Expression of a truncated form of KIT tyrosine kinase in human spermatozoa correlates with sperm DNA integrity. Hum Reprod. 2010;25:2188-2202. doi:10. 1093/humrep/deq168

29. Muratori M, Marchiani S, Maggi M, Forti G, Baldi E. Origin and biological significance of DNA fragmentation in human spermatozoa. Front Biosci. 2006;11:1491-1499. doi:10.2741/1898

30. Erenpreiss J, Spano M, Erenpreisa J, Bungum M, Giwercman A. Sperm chromatin structure and male fertility: biological and clinical aspects. Asian J Androl. 2006;15:217-221.

31. Dockery F, Bulpitt CJ, Donaldson M, Fernandez S, Rajkumar C. The relationship between androgens and arterial stiffness in older men. J Am Geriatr Soc. 2003;51:1627-1632. doi:10.1046/j.1532-5415. 2003.51515.x

32. Fogari R, Zoppi A, Preti P, et al. Sexual activity and plasma testosterone levels in hypertensive males. Am J Hypertens. 2002;15:217-221. doi:10.1016/S0895-7061(01)02280-4

33. Svartberg J, Vo Muhlen D, Schirmer H, Barrett-Connor E, Sundfjord J, Jorde R. Association of endogenous testosterone with blood pressure and left ventricular mass in men. The Tromso Study. Eur J Endocrinol. 2004;150:65-71. doi:10.1530/eje.0.1500065

34. Eisenberg ML, Li S, Behr B, Pera RR, Cullen MR. Relationship between semen production and medical comorbidity. Fertil Steril. 2015;103:66-71. doi:10.1016/j.fertnstert.2014.10.017

35. Pasqualotto FF, Umezu FM, Salvador M, Borges E, Sobreiro BP, Pasqualotto EB. Effect of cigarette smoking on antioxidant levels and presence of leukocytespermia in infertile men: a prospective study. Fertil Steril. 2008;90:278-283. doi:10.1016/j.fertnstert.20 08.02.123

36. Oyeyipo IP, Raji Y, Bolarinwa AF. Nicotine alters male reproductive hormones in male albino rats: the role of cessation. J Hum Reprod Sci. 2013;6:40-44. doi:10.4103/0974-1208.112380

37. Sepaniak S, Forges T, Gerard H, Foliguet B, Bene MC, MonnierBarbarino $\mathrm{P}$. The influence of cigarette smoking on human sperm quality and DNA fragmentation. Toxicology. 2006;223:54-60. doi:10.1016/j.tox.2006.03.001

38. Sharma R, Harlev A, Agarwal A, Esteves SC. Cigarette smoking and semen quality: a new meta-analysis examining the effect of the 2010 World Health Organization laboratory methods for the examination of human semen. Eur Urol. 2016;70:635-645. doi:10.1016/j. eururo.2016.04.010 
39. Le MT, Nguyen TAT, Nguyen HTT, et al. Does sperm DNA fragmentation correlate with semen parameters? Reprod Med Biol. 2019;18:390-396. doi:10.1002/rmb2.12 297
40. Lu JC, Jing J, Chen L, et al. Analysis of human sperm DNA fragmentation index (DFI) related factors: a report of 1010 subfertile men in China. Reprod Biol Endocrinol. 2018;16(1):23. doi:10.1186/ s12958-018-0345-y

Diabetes, Metabolic Syndrome and Obesity: Targets and Therapy

\section{Publish your work in this journal}

Diabetes, Metabolic Syndrome and Obesity: Targets and Therapy is an international, peer-reviewed open-access journal committed to the rapid publication of the latest laboratory and clinical findings in the fields of diabetes, metabolic syndrome and obesity research. Original research, review, case reports, hypothesis formation, expert opinion and commentaries are all considered for publication. The manuscript management system is completely online and includes a very quick and fair peer-review system, which is all easy to use. Visit http://www.dovepress.com/testimonials.php to read real quotes from published authors. 